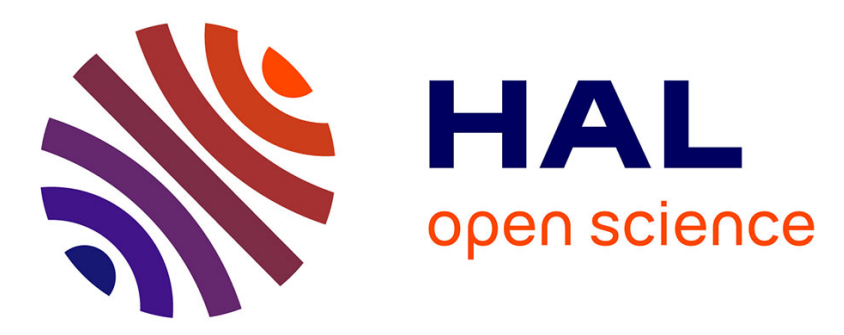

\title{
Geographic Cellular Automata for Realistic Urban form Simulations: How Far Should the Constraint be Contained?
}

\author{
Jean-Philippe Antoni, Gilles Vuidel, Hichem Omrani, Olivier Klein
}

\section{- To cite this version:}

Jean-Philippe Antoni, Gilles Vuidel, Hichem Omrani, Olivier Klein. Geographic Cellular Automata for Realistic Urban form Simulations: How Far Should the Constraint be Contained ?. Luca D'Acci. The Mathematics of Urban Morphology, Birkhäuser Basel; Springer Nature Switzerland AG, pp.147162, 2019, Modeling and Simulation in Science, Engineering and Technology, 978-3-030-12381-9. 10.1007/978-3-030-12381-9_7 . hal-02087028

\section{HAL Id: hal-02087028 \\ https://hal.science/hal-02087028}

Submitted on 1 Apr 2019

HAL is a multi-disciplinary open access archive for the deposit and dissemination of scientific research documents, whether they are published or not. The documents may come from teaching and research institutions in France or abroad, or from public or private research centers.
L'archive ouverte pluridisciplinaire HAL, est destinée au dépôt et à la diffusion de documents scientifiques de niveau recherche, publiés ou non, émanant des établissements d'enseignement et de recherche français ou étrangers, des laboratoires publics ou privés. 


\section{Geographic cellular automata for realistic urban form simulations: how far should the constraint be contained?}

Jean-Philippe Antoni ${ }^{1}$ - jean-philippe.antoni@u-bourgogne.fr

Gilles Vuidel ${ }^{1}$

Hichem Omrani ${ }^{2}$

Olivier Klein ${ }^{2}$

${ }^{1}$ Laboratoire ThéMA, UMR 6049 French National Centre of Scientific Research (CNRS), University of Bourgogne-Franche-Comte

${ }^{2}$ Luxembourg Institute of Socio-Economic Research, Maison des Sciences Humaines, Luxembourg

This is a postprint version, the definitive version of this chapter has been published in D'Acci, L. (Éd.). (2019). The Mathematics of Urban Morphology.

https://www.springer.com/gb/book/9783030123802

DOI : 10.1007/978-3-030-12381-9_7 


\title{
Geographic Cellular Automata for Realistic Urban form Simulations: How Far Should the Constraint be Contained?
}

\author{
Jean-Philippe Antoni, Gilles Vuidel, Hichem Omrani and Olivier Klein
}

\begin{abstract}
Cellular automata (CA) are discrete models that are being ever more widely used to study urban forms and, more broadly, to understand, simulate, and forecast land use changes (LUC). But LUC models are not based on CA dynamics alone and so they are not fully consistent with mathematical definitions of CA. Accordingly, to study urbanization, authors often use "constraint CA" or "geographic CA" (GCA), i.e., CA which are coupled with other models in order to integrate geographical assumptions related to urban form and to provide more realistic results. These complementary models are usually calibrated according to expert knowledge and do not lead to reproducible deterministic results. Consequently, there is often a sizeable gap between the theory of CA as defined in mathematics and their practical use for LUC. In this chapter, cellular automata are constrained by a Markovian process helping to determine the number of cells that can change from one land use category to another. Second, a potential model is used to create a suitability map and define the probability of a cell changing from one category to another. Finally, all these additional constraints lead to a suite of models which is clearly more complex than classical CA as it can be considered mathematically. Nevertheless, as far as possible, it presents GCA as a mathematical adaptation of CA integrating the geographical assumptions necessary for studying urban forms in a realistic way.
\end{abstract}

Keywords Cellular automata $\cdot$ Markov chain $\cdot$ Potential model $\cdot$ Urban form $\cdot$ Spatial modeling

J.-P. Antoni $(\bowtie) \cdot G$. Vuidel

Laboratoire ThéMA, UMR 6049—CNRS et Université Bourgogne

Franche-Comté, 6 Boulevard Gabriel, 21000 Dijon, France

e-mail: jean-philippe.antoni@u-bourgogne.fr

H. Omrani · O. Klein

Luxembourg Institute of Socio-Economic Research, Maison des

Sciences Humaines, 11, Porte des Sciences, 4366 Esch-sur-Alzette,

Belval, Luxembourg 


\section{Introduction}

Urban form may be defined as the relationship between buildings and open spaces within agglomerations or different types of urban aggregates according to the specificities of local context. It refers more specifically to the outer envelope or contours of the city (Antoni 2008). This form, which is characterized by developments at different scales (from the entire agglomeration to a single building), is the result of human occupation of the territory. As a result of individual behaviors, it reflects urban lifestyles generated through several factors such as the urban fabric, the built environment, density/compactness, and the spatial distribution of activities and facilities.

Geographers tackling urban forms seek primarily to understand the mechanisms that lead to the current form of a given urban context, to provide procedures for designing optimal forms, and to simulate future developments. Such approaches rely on adapted modeling tools that integrate features based on explanatory and predictive models, which can be used as tools to support reflection and decisionmaking. Among the mathematical models, many computer-based solutions attempt to simulate the evolution of cities and specially to understand how urban forms change over time, past and/or future. Among them, cellular automata (CA) stand out as a form of mathematical computation models based on a discrete dynamic modeling system. They are structured into procedures based on the nesting of simple rules that reflect the complexity of real systems. This approach is attractive because it relies on a generic development principle that fits very well with the way systems in general, and urban systems in particular, evolve. In this framework, LucSim ${ }^{1}$ was designed and developed by ThéMA Laboratory (Antoni et al. 2017) as a cellular automata model specially designed for geographical analysis and spatial simulation for both researchers and advanced planning institutes. This user-friendly software is well adapted for analyzing and simulating land use changes and spatial dynamics at different scales for decision-making in urban and land planning.

After having recalled some definitions of CA as used in geography, the next section shows why they remain difficult to apply directly to concrete urban form planning or studies. Section 3 then presents two major constraints (temporal and spatial) that can improve CA simulation results by refining basic assumptions related to land use change. Section 4 presents the results in a new theoretical CA formalization, leading to more realistic urban form simulations illustrated by the example of Wroclaw in Poland. These results are then discussed in Sect. 5 questioning the extent to which these constraints need to be contained.

\footnotetext{
${ }^{1}$ See https://sourcesup.renater.fr/lucsim/ for more details.
} 


\section{CA-Based Discrete Modeling}

Starting from a formal definition of CA-based discrete modeling, this section focuses on the strengths and limitations of this type of approach when considering urban form simulations.

\subsection{CA Formal Definition}

CA are discrete computer models composed of a grid of regular cells assigned to one particular state (among a finite number of states) which may change into another state over time. They were invented in the 1940s through the works of S. Ulam and J. von Neumann (1963) and popularized in the 1970s by John Conway's Game of Life (Conway 1970). Initially, they were of interest only to a few theorists of mathematics or computer science, who used them to solve puzzles or to build mathematical games in scientific journals. In the 1980s, a number of papers, especially those of Wolfram $(1983,1985)$ made CA fashionable, or rather showed them in a new light with a multitude of possible applications for very different fields. Having been focused initially on problems in physics and chemistry, several innovative experiments opened up biology, medicine, and ecology to CA before they were introduced into spatial studies, particularly geography and urban planning. In geography, the use of CA indeed echoes the cellular conception of geographical space defended by Tobler (1979) and Couclelis (1985) and reveals the deeply geographical character of this kind of tool (Couclelis 1988). For these authors, this cellular conception is more advantageous than considering space through the irregular spatial polygons defined by political and administrative jurisdictions. It provides a notational simplification allowing a cell of an array to be indexed in the same way as in matrix algebra. In such a notation, $g_{i j}^{t}$ is a cell characterized by a land use category (urban, forest, industry, etc.) at the location $i, j$ at time $t$, and $g_{i j}^{t+\Delta t}$ corresponds to the change in the land use category at the same location at time $t+t$.

From this basis, Tobler (1979) was probably the first geographer to envisage and describe all the formal possibilities of cell transitions according to different processes involving their neighborhood (Fig. 1):

1. An independent model where $g_{i j}^{t+\Delta t}$ is not related to $g_{i j}^{t}$ in any way.

2. A dependent model where the land use at location $i, j$ at time $t+t$ depends on the previous land use at that location, such that $g_{i j}^{t+\Delta t}=f\left(g_{i j}^{t}\right)$.

3. An historical model where the land use at position $i, j$ in the future depends on the initial land uses at that location, such that $g_{i j}^{t+\Delta t}=$ $f\left(g_{i j}^{t}, g_{i j}^{t-\Delta t}, g_{i j}^{t-2 \Delta t}, \ldots, g_{i j}^{t-k \Delta t}\right)$.

4. A multivariate model where the land use at location $i, j$ is dependent on several other variables at that location, such that $g_{i j}^{t+\Delta t}=f\left(u_{i j}^{t}, v_{i j}^{t}, w_{i j}^{t}, \ldots, z_{i j}^{t}\right)$. 
Tobler's

\section{Cells transitions models}

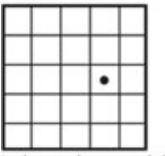

Independant model

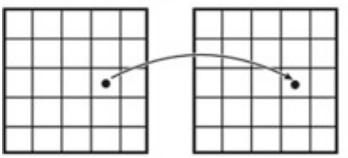

Dependant model

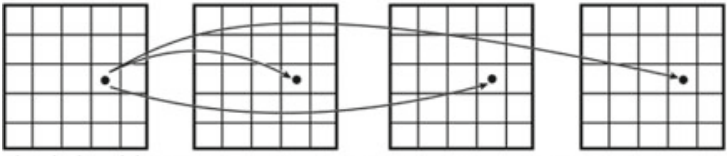

Historical model
Multivariate model

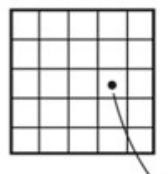

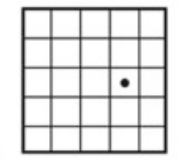

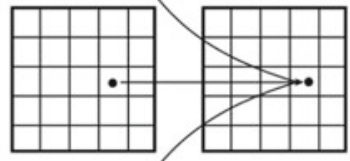

Geographical

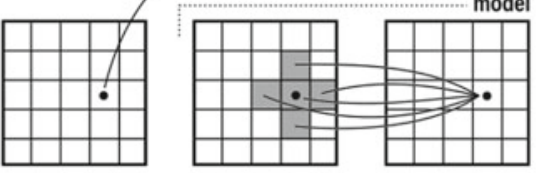

model

From Tobler W. (1979)

Cellular geography.

In: Gale, S. and Olsson, G. (Eds.)

Philosophy in Geography, Reidel, 379-386.

Fig. 1 Tobler's cells transitions models

5. A geographical model where the land use at location $i, j$ is dependent on the land use at other locations, such that $g_{i j}^{t+\Delta t}=f\left(g_{i+p, j+q}^{t}\right)$.

This fifth model clearly corresponds to the process implemented in most CA models. Nevertheless, in the field of spatial studies and geographical sciences, formal definitions remain rare except for Tobler's former theoretical formalization. Researchers using CA seldom take the time to describe the mathematical form of the model they are using and refer only to other fundamental papers (White and Engelen 1993; Benenson and Torrens 2004), or describe CA as if-then-else algorithms (Batty 1997). Torrens (2000) is one of the rare geographers to use a mathematical notation to define the principles of CA transition according to the geographical process (fifth model) defined by Tobler.

\subsection{CA Limits}

A Tobler-like geographical notation is clearly pleasant mathematically and correctly describes how a transition can operate from one cell state to another according to theoretical neighboring configurations. But despite this advantage, it does not model land use change in an operative way, nor does it reproduce or create realistic simulations. An illustrative example based on a case study of Wroclaw (Poland) helps to explain why. 

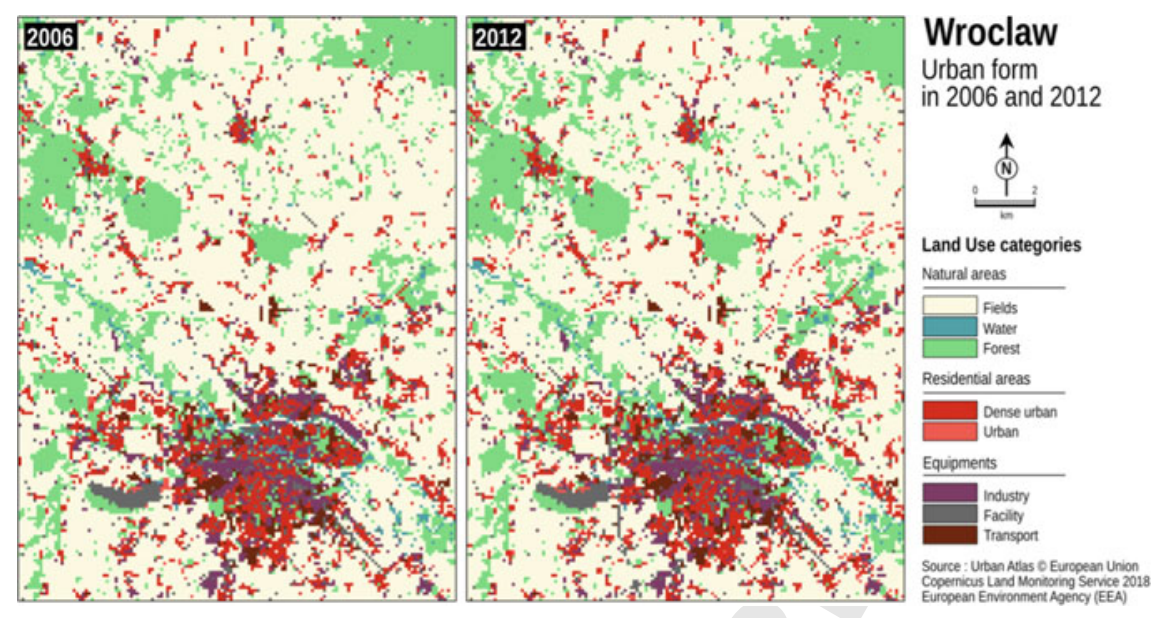

Fig. 2 The urban form of Wroclaw in 2006 and 2012

This example is built using data from the Urban Atlas (Copernicus Programme) ${ }^{2}$ which describes land use in 2006 and 2012. As shown in Fig. 2, land use is classified into eight categories: water, fields, forest, dense urban, urban, industry, facilities, and transport. To simulate the evolution of this territory in the future, we use four transition rules implemented in the LucSim CA software (Antoni et al. 2017). These rules are constructed from expert knowledge and are supposed to reproduce urban expansion based on simple principles that have largely determined the evolution of urban form in the past. Rules are here expressed in two ways: verbal language and their conversion into a computer-based language specific to LucSim software (dashes):

1. Fields will become urban if, within a neighborhood of two cells, the current cell is surrounded by at least $10 \%$ of urban and dense urban cells, if, within a neighborhood of fifteen cells, there is at least one cell of facilities, if there is no direct connection to forest (within a neighborhood of one cell), and if within a neighborhood of three cells less than $50 \%$ of the cells are urban and dense urban:

- Fields -> Urban: pCellCir(Urban,2) + pCellCir(Urban_dense,2) + pCell$\operatorname{Cir}($ New, 2) $>=10 \%$ and nbCellCir(Facilities, 15) $>=1$ and nbCell$\operatorname{Cir}($ Forest, 1$)<=1$ and pCellCir(Urban,3) $+p \operatorname{CellCir}($ Urban,3) $<=50 \%$;

2. Urban cells will be densified if they are completely surrounded by urbanized areas within a neighborhood of one cell:

- Urban -> Urban_dense: pCellCir(Urban,1) =100\%;

${ }^{2}$ See https://land.copernicus.eu/about for more details. 
3. Urban parks (forests) will be created from urban or dense urban if the density of urbanized areas is more than $90 \%$ within a small radius (within a neighborhood of 2 cells for an urban category and within a neighborhood of 1 cell for a dense urban category):

- Urban -> Forest: pCellCir(Urban,2) + pCellCir(Urban_dense,2) >=90\%;

- Urban_dense -> Forest: pCellCir(Urban,1) + pCellCir(Urban_dense,1) >= $90 \%$;

However, the strict application of these rules within LucSim produces results that have nothing to do with the current land use, nor with any logical development from a town planning or land use planning perspective.

Figure 3 indeed shows resulting spatial configurations, which are supposed to reproduce an urban sprawl process. It clearly shows that the urban sprawl process simulated by the model leads to a credible expansion of the urban form during the first iterations of the CA run, with an expansion of the city taking the form of an oil slick. But very quickly, the number of newly urbanized cells produced by the

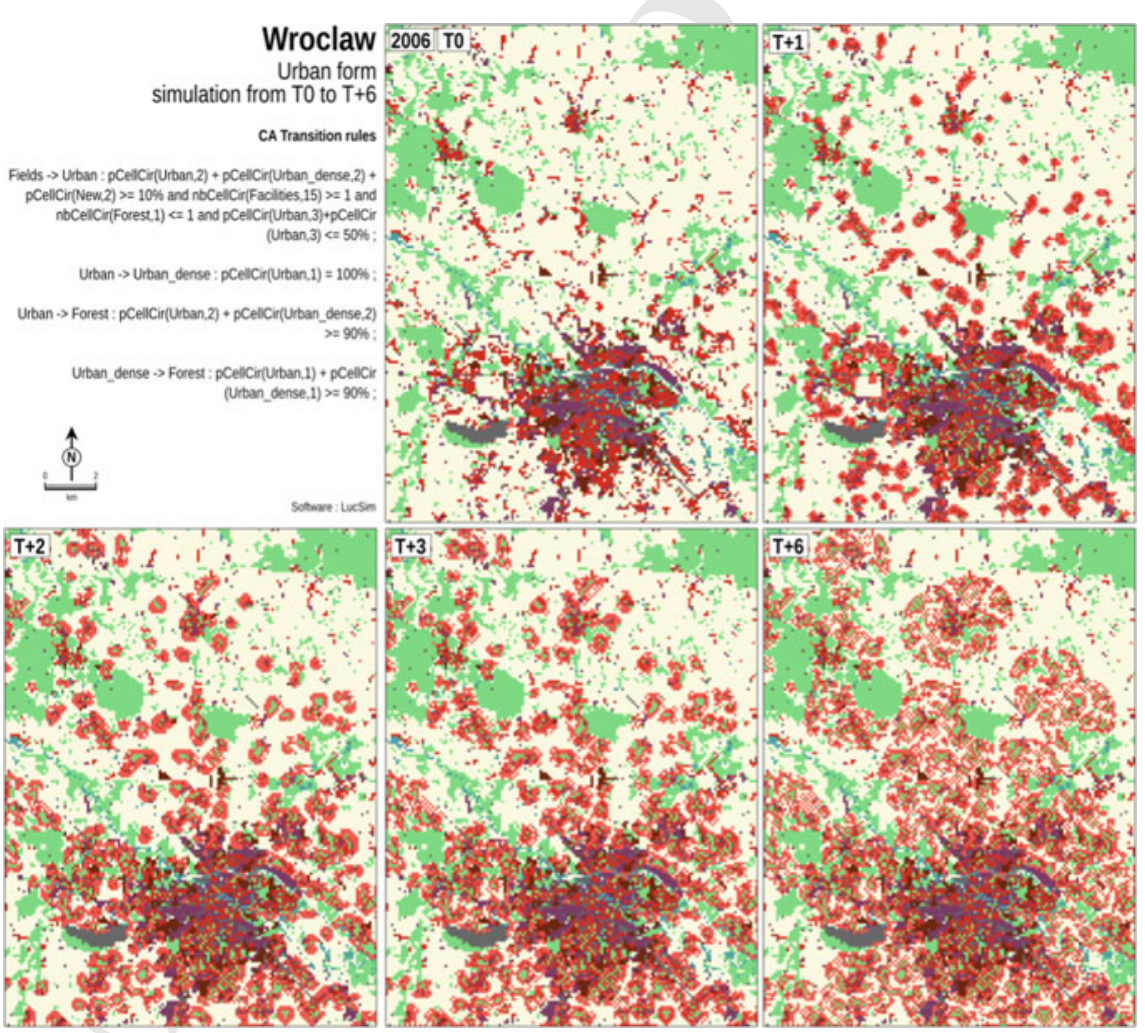

Fig. 3 Simulation of the urban form of Wroclaw from $T 0$ to $T+6$, (To make the images easier to read, newly urbanized areas appear in black before returning to their original color (red)) 


\section{Wroclaw}

Land Use change simulation from T0 to $\mathrm{T}+15$

Sofware : LucSim
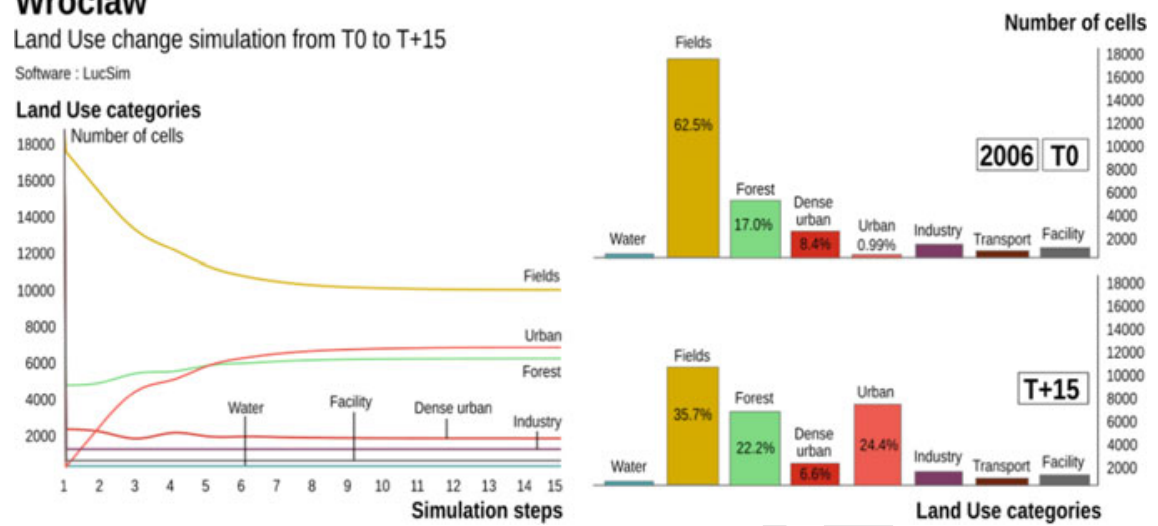

Fig. 4 Land use changes in Wroclaw from $T 0$ to $T+15$

model generates a snowball effect that far exceeds any realistic forecast of future urbanization for a city like Wroclaw.

From this example, we can conclude that the simple use of CA with transition rules is not sufficient for forecasting realistic and operational simulations of urban forms. On the one hand, the recognition of spatial patterns leading to the application of a transition rule corresponds only very partially to the reality of the urbanization process. Indeed, the number of possible transitions appears to be much greater than the real needs in terms of new housing and population growth. On the other hand, the results give no information about the timing of this urbanization. Therefore, although it seems clear that a time step does not correspond to a regular and stable duration, we are unable to say whether the images produced from $t+1$ to $t+16$ lead us to 2020, 2050, 2200, or 3500 (Fig. 4).

It appears clearly, then, that a CA cannot be directly applied to simulate city growth and more generally land use change. It must necessarily be constrained to answer more precise questions about space and time, so that the results produced can be integrated more easily, and realistically within a range of analysis and decisionmaking for planning. Only these kinds of constraints, based on assumptions about urban form, enable CA to be used in geography and allow for the fundamental difference between classical mathematical cellular automata and geographic cellular automata (GCA).

\section{Suitable Constraints for Urban Modeling}

There are many methods by which to constrain CA and the literature abounds with examples using several methods and models. In this section, we shall focus on just two kinds of fundamental constraints. The first is a time constraint to situate the results 
produced by the automaton over time. As in many publications (Arsanjani et al. 2013), it relies on a Markov chain process. The second constraint is a space constraint, which aims to reduce the number of neighboring configurations for possible transitions and focuses on the most realistic of them. It is based on a potential model.

\subsection{Temporal Constraint}

The first step uses a Markov chain to constrain the process of land use change in quantitative terms. Comparison of two static land use images $(2006,2012)$ can be used to determine what has happened between each image and so formulate a transition process. By comparing the land use categories date by date and cell by cell, it is possible to determine cellular changes between $t$ and $t+1$ and to identify the land use dynamics. Theoretically, each cell can either change from one land use category to another or remain in its initial category. The dynamics of the model can therefore be presented as a series of possible transitions from one land use category $k$ at time $t$ to another land use category $l$ at $t+1$. For a given cell $N_{i}$, a transition $\Delta$ can be written as:

$$
\Delta \mathrm{N}_{\mathrm{i}, \mathrm{kl}}=1 \text { if } N_{\mathrm{i}, \mathrm{k}}(t)=1 \text { and } N_{\mathrm{i}, 1}(\mathrm{t}+1)=1
$$

To simplify the complexity resulting from the large number of cells and possible transitions, changes can be aggregated by land use categories. The aggregate transition for the complete system is then

$$
\Delta \mathrm{N}_{\mathrm{kl}}=\sum_{\mathrm{i}=1}^{n} \Delta \mathrm{N}_{\mathrm{i}, \mathrm{kl}}
$$

This formulation allows us to build a contingency matrix indicating the number of cell transitions from a category $k$ to a category $l$ between $t$ and $t+1$ (i.e., between 2006 and 2012). This matrix can be easily converted into a transition matrix indicating the probability of change between all land use categories (Table 1). When associated with the previous vectors, this matrix provides all the elements needed for the construction of a Markov chain (MC). In the literature, an MC is defined as a mathematical process where transition probabilities are conditional on the past, and express the state of a variable at a time $t$ as a function of observations of this variable at $t-$ 1 (Feller 1968, Berchtold 1998). It relies on the connection of three items: (i) the description of the relative values associated with an initial state (land uses visualized as a vector for example); (ii) a transition matrix expressing the transition probabilities of different groups of observations from one category to another; and (iii) a diachronic transformation by an operator in the form of a matrix multiplication iteration.

If we follow this procedure, land use at time $t+1$ can be simulated by multiplying the corresponding vector at time $t$ by the corresponding contingency matrix, after the 
Table 1 The transition matrix for Wroclaw between 2006 and 2012

\begin{tabular}{l|l|l|l|l|l|l|l|l}
\hline & Water & Fields & Forest & Dense U & Urban & Industry & Facilities & Transp. \\
\hline Water & $\mathbf{9 8 . 7 8 4}$ & 0.608 & 0 & 0 & 0.304 & 0 & 0 & 0.304 \\
\hline Fields & 0.08 & $\mathbf{9 6 . 8 4 9}$ & 0.017 & 0.028 & 2.178 & 0.364 & 0.034 & 0.049 \\
\hline Forest & 0 & 0.063 & $\mathbf{9 9 . 5 6 1}$ & 0 & 0.104 & 0.125 & 0 & 0.146 \\
\hline Dense U & 0 & 0 & 0 & $\mathbf{9 9 . 8 3 1}$ & 0.042 & 0.085 & 0.042 & 0 \\
\hline Urban & 0 & 5.755 & 0.719 & 11.151 & $\mathbf{6 9 . 7 8 4}$ & 6.475 & 0.719 & 5.396 \\
\hline Industry & 0 & 0.558 & 0 & 0 & 1.275 & $\mathbf{9 8 . 0 8 8}$ & 0 & 0.08 \\
\hline Facilities & 0 & 0 & 0.159 & 0.638 & 1.115 & 0.159 & $\mathbf{9 7 . 4 4 8}$ & 0.478 \\
\hline Transp & 0 & 0 & 0 & 0 & 0.662 & 0 & 0 & $\mathbf{9 9 . 3 3 8}$ \\
\hline
\end{tabular}

transformation of the latter into transition probabilities from one land use category $k$ to another $l$. To transform observed contingencies into transition probabilities, we use the following:

$$
p_{\mathrm{kl}}(\mathrm{t})=\frac{\Delta \mathrm{N}_{\mathrm{kl}}}{N_{k}(t)} \text { and } \sum_{\mathrm{k}=1}^{m} p_{\mathrm{kl}}(t)=1
$$

We then consider the MC as follows:

$$
\begin{gathered}
N_{\mathrm{i}}(\mathrm{t}+1)=\sum_{\mathrm{k}=1}^{m} p_{\mathrm{kl}} \cdot N_{k}(t) \\
\text { where } p_{\mathrm{kl}}=\frac{\Delta \mathrm{N}_{\mathrm{kl}}}{N_{k}(t)}=\frac{\Delta \mathrm{N}_{\mathrm{kl}}}{\sum_{l} \Delta \mathrm{N}_{\mathrm{kl}}} \text { and } \sum_{l} p_{\mathrm{kl}}=1
\end{gathered}
$$

According to this formulation, the MC process gives us the chance to prospectively calculate future states from known past states, based on observation of past trends and probabilities. According to the method, this calculation is based on the assumption that future changes will follow the trend of past changes, but as it is based on a matrix calculation, this trend is not necessarily linear. Moreover, the values of the transition matrix can also be modified by users of the model to integrate different parameters for the quantification of future land use changes. In our case, LucSim uses the original transition matrix to calculate the number of cells in each land use category in 2018, 2024, 2030, etc., on the basis of 2006 and 2012 land uses (same interval of 6 years between each date). This system gives us a more plausible picture of urban dynamics by calculating land use vectors for each future date, as presented in Table 2.

This table also indicates that the total number $n_{l, t}$ of cells that should be urbanized in 2030 must not exceed 984 "urban" cells and 2571 "dense urban" cells. 
Table 2 Expected future land use vectors

\begin{tabular}{l|l|l|l|l|l|l|l|l}
\hline & Water & Fields & Forest & Dense U & Urban & Industry & Facilities & Transp. \\
\hline $\mathbf{2 0 1 8}$ & 339 & 17058 & 4771 & 2401 & 613 & 1322 & 620 & 1006 \\
\hline $\mathbf{2 0 2 4}$ & 348 & 16568 & 4758 & 2474 & 836 & 1407 & 615 & 1121 \\
\hline $\mathbf{2 0 3 0}$ & 357 & 16107 & 4747 & 2571 & 984 & 1504 & 612 & 1245 \\
\hline
\end{tabular}

\subsection{Spatial Constraint}

Among other methods, MCs are a way to quantify future land use changes when space is considered through cells. However, they say nothing about the location of those changes. The places where changes occur are strictly determined by the transition rules of the CA. To integrate information known elsewhere about the spaces most likely to be urbanized quickly (or on the contrary not to be if they are protected), it is therefore mandatory to add a second constraint capable of determining the most suitable locations. This second constraint is relatively conventional using GCA and is usually based on expert knowledge. It consists of constructing a suitability map based on driving factors, namely geographical features that are supposed to influence urbanization (Clarke 2008).

It seems obvious that working on locations requires a theoretical framework for geographical space. It is not surprising, then, that geographers have developed many models for this, often dedicated to residential location (Putman 1979). Diffusion models, for example, are spatial models that make it possible to locate certain elements on the assumption that they are generated through the diffusion of other elements. Fractal models are other models that can also simulate urban growth (Batty 2007). The city is then considered as a system that maximizes interactions between the elements it contains. Spatial interaction models are also another family of models derived from Newton's law of universal gravitation. They are based on identical principles and make it possible to locate changes where they are complementary to those around them by minimizing the distances between them. They have been used for calculating areas of traffic or influence (Helvig 1964) and for estimating residential or industrial locations (Abler et al. 1972).

Among spatial interaction models, potential models indicate that the probability of there being a relationship between places decreases with distance. Basically, they are used to measure "accessibility" aiming to evaluate the variation of the relative amount of relationship opportunity depending on the position of all places. Generally, the potential of a place is calculated from the analysis of the importance of all the other points of the system, an importance that is termed "mass" in reference to the Newtonian gravity model. The potential of a cell is usually the sum of all the potentials created at that location by the set of individual masses that make up the system (i.e., all the other cells). The calculation of the potential $P$ of each point $i$ therefore consists in applying to them a formula simultaneously taking into account the mass value $m$ of all the points $j$ located in a geographical area as a function of the 

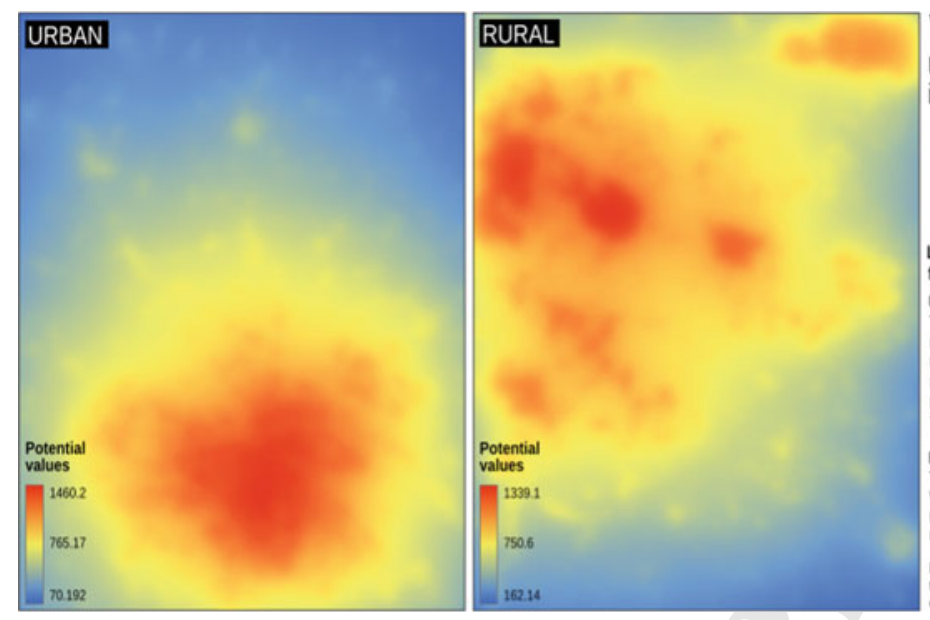

Wroclaw

Urban form

in 2006 and 2012

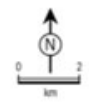

Land uses masses

for the two scenarios

Urban densification

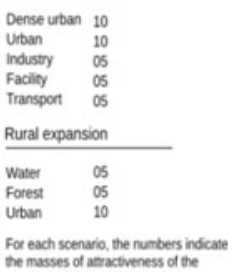

Fig. 5 Two contrasting realistic potential models

distance $d_{i j}^{\alpha}$ separating those points from the one for which the calculation is made. The operative formula is defined as follows:

$$
P_{i}=\sum_{j=1}^{n} \frac{m_{j}}{d_{i j}^{\alpha}}
$$

Spatial constraints based on potential results were applied to the case study of Wroclaw by distinguishing two contrasting scenarios. The first scenario (S1) focuses on "Urban densification" and assigns significant masses to Dense urban and Urban $(\mathrm{m}=10)$ categories and medium masses to Industry, Facility, and Transport $(\mathrm{m}=5)$ categories. As a result, the potential map (Fig. 5, left) shows high potential for land use change around the heart of the city of Wroclaw. Areas with high potential for change-urbanization - are limited to very closed urban areas. The second scenario (S2) deals with "Rural expansion" and assigns significant masses to Urban $(\mathrm{m}=10)$ and medium masses to Forest and Water $(\mathrm{m}=5)$ categories. Therefore, in this case, the potential map (Fig. 5, right) highlights more sprawling areas with high potential for change, mainly in the northwestern part of the study area, relatively far from Wroclaw city center.

\section{Constraint Geographical CA}

Based on the spatiotemporal constraints presented in Sect. 3, a new more integrated formalization of CA can be proposed. In this new formula, the state of a cell $i$ at step $t+1$ still depends on the state of the cell at step $t\left(c_{j, t}\right)$ and the state of the cells in 
the neighborhood $\left(V_{i, t}^{r}\right)$. This relation is clearly based on the classical CA definition defined par Tobler or Torrens (Sect. 2). But, it also integrates the MC results limiting land use development to within a number $n_{t}$ of cells for each land use category. Moreover, the suitability of the simulations calculated by the CA is dependent on the cell's potential $P_{i}$ based on land use attractiveness masses and distances. A synthetic expression of the model could be written

$$
c_{i, t+1}=f\left(c_{i, t}, V_{i, t}^{r}, n_{l, t}, P_{i}\right)
$$

where $n_{t}=$ was defined in Sect. 3.1 and $P_{i}$ was defined in Sect. 3.2.

This formula corresponds to the CA process integrated in the LucSim software and was applied to produce two contrasting and realistic scenarios in the case study of Wroclaw in 2006 and 2012. Scenario S1 seeks to densify the more urbanized areas in a pronounced manner. This urban development is thus concentrated around the previously densely built-up areas and seeks to fill the open space corresponding to fields or less dense urban categories. $\mathrm{S} 2$ is a peri-urban development scenario which takes place around villages relatively far from the most urbanized areas, where the fields have high potential for change into the less dense urban category.

Moreover, for each scenario, MCs make it possible to quantify future urbanization by 2030 by estimating the number of cells that change from a nonurban to an urban state with a distinction between two categories: urban and dense urban categories for the years 2018, 2024, and 2030 (Table 2). In a second step, two contrasting suitability maps (Fig. 5) constrain the spatial development according to the weighting of each land use category. The resulting suitability maps based on the potential model (Fig. 5) show two contrasting potentials for development: one that is more concentrated around the city core for $\mathrm{S} 1$, and the other that is more dispersed in the center and northern part of the case study for S2. Then in a third step, based on the results of steps 1 and 2, the AC could be run according to the three rules set out in Sect. 2.2.

As expected, S1 concentrates on urban development in the southern part of the study area around the core of Wroclaw. This concentration around the core is accompanied by a few outgrowths mainly in the northwestern and northeastern parts of the city. By contrast, S2 reveals a marked expansion in the urban category in the more rural northwestern part of the study area. Urbanization there is less dense and takes on more the form of urban sprawl. As can be seen from the example, LucSim makes it easy to simulate urban development scenarios and their consequences for urban forms, on the one hand reinforcing the compactness of the city and on the other fostering its expansion in rural areas. This kind of modeling process helps in inter- 


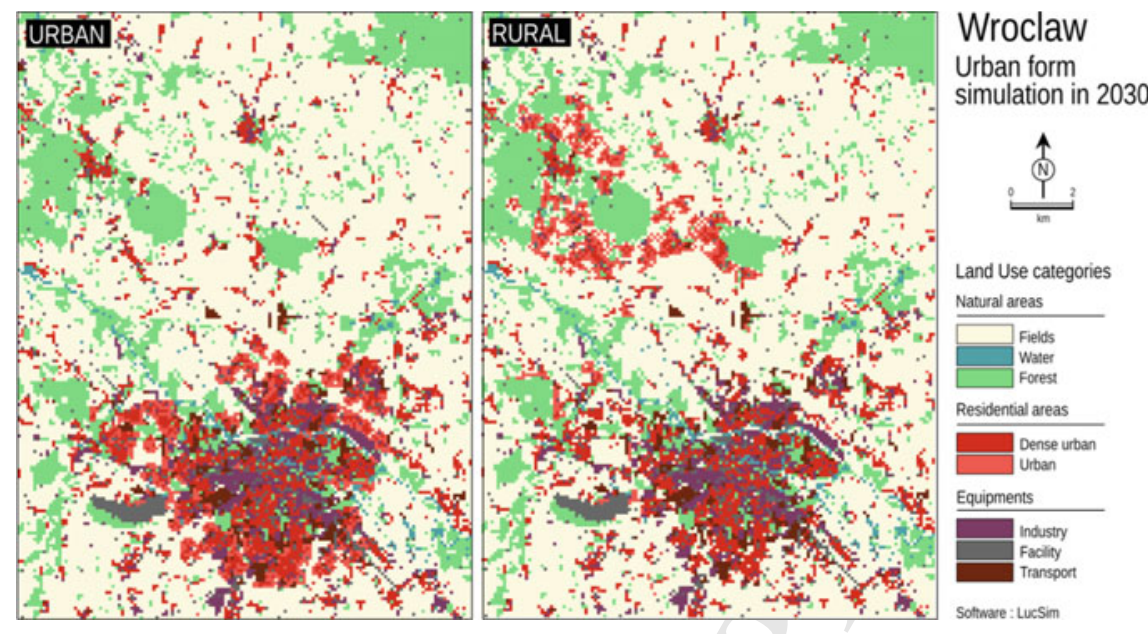

Fig. 6 Simulation of two contrasting scenarios by 2030

actively analyzing the direct consequences of spatial planning policies. Finally, it is also important to emphasize that by integrating space and time constraints, the simulation results are made much more realistic than in the total absence of constraints (Fig. 6).

\section{Discussion}

The results presented in the previous section are certainly consistent, but they raise a number of questions that call for discussion. First, the CA is driven by a dual constraint system applied to the initial transition rules. However, although there is no prior theoretical, conceptual, and formal incompatibility between the Markovian model and the potential model, some inconsistencies may appear in its actual use. For example, constraints derived from MCs, such as the transition rules themselves, apply at the level of the land use categories. They are dependent on each transition involving two-to-one states. On the other hand, the potential model produces a result applicable for all of these categories. It is therefore independent of transitions and less precise. One solution to overcome this problem would be not to calculate one single potential model, but as many potential models as there are transitions by calibrating each of them on masses of attractiveness corresponding actually and more precisely to this transition. Such a solution might be attractive in theory, but in practice, it makes modeling increasingly more complex by multiplying the problems of calibration, which were already questionable in the example discussed here.

The calibration of models also raises a second set of questions. Among the models used here, only MCs can be considered "autonomous" since they automatically 
produce results from two original images. The potential model and the definition of the transition rules require the use of expert knowledge. In the current state of our knowledge about the growth of urban forms, such recourse is a qualitative input that does not guarantee the reproducibility of the results produced by the modeling in any way. Moreover, insofar as these parameters are not directly derived from mathematical calculation, they appear questionable. This fundamental point is obviously a limitation for the modeling exercise and for the application of mathematical tools for forecasting urban forms. To overcome this problem, many authors have proposed to use "machine learning" approaches so that transition rules are automatically generated based on known past states. Indeed, recent work simulates transitions using decision trees (Samardžić-Petrović et al. 2015) or artificial neural networks (Li and Yeh 2002; Almeida et al. 2008; Tayyebi et al. 2011). Although still very exploratory, the results obtained so far seem promising and, through artificial intelligence processes, they offer an additional step to mathematical and geographical modeling.

But finally, these recent developments also raise the question of the importance of expert knowledge in forecasting urban growth. The results produced in this field are often considered as "images of the future" leading to a collective reflection on the future of territories, rather than final results. Given our difficulty in predicting the future, and the fact that it is very unlikely that this future will be a mere reproduction of the past, it is clear that these results will probably be wrong in the long run (Antoni 2016). Consequently, using expert knowledge to involve local actors in defining a common future does not seem completely absurd. In essence, these reflections on CA calibration ask how far the constraint should be contained. Depending on their objectives, anyone can define the level of constraint they wish to apply to simulate land use change, from a calibration entirely defined by mathematical models or totally derived from expert knowledge. The best way might be a mixed approach combining both machine learning and expert knowledge.

\section{Conclusion}

After having shown the necessity for constraining CA in the study of urban forms, this paper has proposed a mathematical formalization for specific geographic cellular automata (GCA) implemented in LucSim software. At this level of detail, such a formalization adapted to the social sciences is rare in the literature and therefore appears as one of the fundamental originalities of this chapter. In particular, it aims to link the cellular design of geographical space, the Markovian approach to transition processes, the distance weighting included in gravity models (potential), and the phenomenon of emergence that defines artificial intelligence models in a single formal notation. That's not so bad! In addition, the results produced using this set of methods and models appear quite realistic and are able to correctly reproduce a credible process of urban growth. But at the same time, this reproduction remains open to the intricacy of planning scenarios and allows us to consider a wider use 
of CA in the framework of a more operational territorial forecast. And that's even better!

Finally, in a more general way, this chapter also shows that it is worth transferring methods developed in mathematics, physics, computer sciences, or mathematics to the social sciences. This transfer obviously requires a substantial effort of abstraction and what may be considerable investment for researchers or developers who are not immediately comfortable with mathematical tools. But since the quantitative revolution started by geographers in the 1960s (Burton 1963), this approach is currently enabling us to work the latest advances in artificial intelligence for decision support into urban and land use planning.

\section{References}

Abler, R., Adams, J.S., Gould, P. (1972) Spatial Organization. The Gepgrapher's Viaw of the World, Prentice/Hall International, 587 p.

Almeida, C., Gleriani, J., Castejon, E., Soares-Filho, B. (2008) Using neural networks and cellular automata for modelling intra-urban land-use dynamics. International Journal of Geographical Information Science, 22(9), 943-963.

Antoni, J.P. (2008) Lexique de la ville, Ellipses, 184 p.

Antoni, J.P. (2016) Concepts, méthodes et modèles pour l'aménagement et les mobilités: l'aide à la décision face à la transition eco-energetique. Economica, $250 \mathrm{p}$.

Antoni, J.P., Judge, V., Vuidel, G., Klein, O. (2017) "Constraint Cellular Automata for Urban Development Simulation: An Application to the Strasbourg-Kehl Cross-Border Area." In: Camacho Olmedo M.T., Paegelow M., Mas J.F., Escobar F. (Eds.) Geomatic Approaches for Modeling Land Change Scenarios, Springer, pp. 293-306.

Arsanjani, J.J., Helbich, M., Kainz, W., Ali Darvishi, B. (2013) Integration of logistic regression, Markov chain and cellular automata models to simulate urban expansion. International Journal of Applied Earth Observation and Geoinformation, 21, 265-275.

Batty, M. (1997) Cellular automata and urban form: A primer. Journal of the American Planning Association, 63:2, 266-274.

Batty, M. (2007) Cities and Complexity: Understanding Cities with Cellular Automata, Agent-Based Models, and Fractals, MIT Press, 592 p.

Benenson, I., Torrens, P.M. (2004) Geosimulation: Automata-Based Modelling of Urban Phenomena. John Wiley, London, UK.

Berchtold, A. (1998) Chaînes de Markov et modèles de transition. Applications aux sciences sociales. Hermes Science Publications, Paris.

Burton, I. (1963) The quantitative revolution and theoretical geography. The Canadian Geographer, 7, 151-162.

Clarke, K.C. (2008) A Decade of Cellular Urban Modeling with SLEUTH: Unresolved Issues and Problems, Ch. 3 in Planning Support Systems for Cities and Regions (Ed. Brail R. K., Lincoln Institute of Land Policy), Cambridge, MA, pp 47-60.

Conway, J. (1970) Mathematical games, Scientific American, October, 120-127.

Couclecis, H. (1985) Cellular world: A framework for modelling micro-macro dynamics. Environment and Planning A, 17, 585-596.

Couclecis, H. (1988) Of mice and men: What rodent populations can teach us about complex spatial dynamics. Environment and Planning A, 20, 99-109.

Feller, W. (1968) An Introduction to Probability Theory and Its Applications. 3rd edition. Wiley. 
Helvig, M. (1964) Chicago's external Truck Movements: Spatial Interactions between the Chicago Area and its Hinterland, University of Chicago, Department of Geography, Research paper, 90, $132 \mathrm{p}$.

Li, X., Yeh, A.G.O. (2002) Neural-network-based cellular automata for simulating multiple land use changes using GIS. International Journal of Geographical Information Science, 16(4), 323-343.

Neumann (von), J. (1963) The General and Logical Theory of Automata. Collected Work, no. 5, Taub, A.H.

Samardžić-Petrović, M., Dragićević, S., Bajat, B., Kovačević, M. (2015) Exploring the decision tree method for modelling urban land use change. Geomatica, 69(3), 313-325.

Tayyebi, A., Pijanowski, B.C., Tayyebi, A.H. (2011) An urban growth boundary model using neural networks, GIS and radial parameterization: An application to Tehran, Iran. Landscape and Urban Planning, 100(1), 35-44.

Tobler, W.R. (1979) “Cellular Geography.” In: Gale S., Olsson G., Philosophy in Geography. Reidel Pub., Dordrecht, Holland, pp. 379-386.

Torrens, P.M. (2000) How cellular models of urban systems work (1. Theory), CASA Working Paper Series.

White, R., Engelen, G. (1993) Cellular automata and fractal urban form: A cellular modelling approach to the evolution of urban land use patterns. Environment and Planning A, 25, 1175-1199.

Wolfram, S. (1983) Statistical mechanics of cellular automata. Review of Modern Physics, 55, 601-644.

Wolfram, S. (2002) A New Kind of Science. Champaign, 549 p. 